\title{
Can dedicated emergency team and area for older people reduce the hospital admission rate? - An observational pre- and post-intervention study
}

\author{
Jenny Liu ${ }^{1 *}$ (D), Therese Palmgren ${ }^{1}$, Sari Ponzer ${ }^{1}$, Italo Masiello ${ }^{2}$ and Nasim Farrokhnia ${ }^{1}$
}

\begin{abstract}
Background: Emergency department (ED) care of older patients is often complex. Geriatric ED guidelines can help to meet this challenge. However, training requirements, the use of time-consuming tools for comprehensive geriatric assessment (CGA), a lack of golden standard to identify the frail patients, and the weak evidence of positive outcomes of using CGA in EDs pose barriers to introduce the guidelines. Dedicating an interprofessional team of regular ED medical and nursing staff and an older-friendly ED area can be another approach. Previous studies of geriatrician-led CGA in EDs have reported a reduced hospital admission rate. The aim of this study was to investigate whether a dedicated interprofessional emergency team also can reduce the hospital admission rate without the resources required by the formal use of CGA.

Methods: An observational pre-post study at a large adult ED, where all patients 80 years or older arriving on weekdays in the intervention period from 2016.09.26 to 2016.11.28 and the corresponding weekdays in the previous year from 2015.09.28 to 2015.11.30 were included.

In the intervention period, older patients either received care in the geriatric module by the dedicated team or in the regular team modules for patients of mixed ages. In 2015, all patients received care in regular team modules.

The primary outcome measure was the total hospital admission rate and the ED length of stay was the secondary outcome measure.
\end{abstract}

Results: We included 2377 arrivals in the intervention period, when $26.7 \%(N=634)$ received care in the geriatric module, and 2207 arrivals in the 2015 period. The total hospital admission rate was 61.7\% (N=1466/2377) in the intervention period compared to 64.8\% ( $N=1431 / 2207)$ in $2015(p=0.03)$. The difference was larger for patients treated in the geriatric module, $51.1 \%$ compared to $62.1 \%$ (95\% Cl: 56.3 to 68.0\%) for patients who would have been eligible in 2015. The ED length of stay was longer in the intervention period.

Conclusions: An interprofessional team and area dedicated to older patients was associated to a lower hospital admission rate. Further studies are needed to confirm the results.

Keywords: Emergency department, Older patients, Hospital admission, Length of stay, Interprofessional, Teamwork

\footnotetext{
* Correspondence: jenny.liu@ki.se

'Department of Clinical Science and Education, Södersjukhuset, Karolinska Institutet, Södersjukhuset AB, KI SÖS, Sjukhusbacken 10, 11883 Stockholm, Sweden

Full list of author information is available at the end of the article
}

(c) The Author(s). 2021 Open Access This article is licensed under a Creative Commons Attribution 4.0 International License, which permits use, sharing, adaptation, distribution and reproduction in any medium or format, as long as you give appropriate credit to the original author(s) and the source, provide a link to the Creative Commons licence, and indicate if changes were made. The images or other third party material in this article are included in the article's Creative Commons licence, unless indicated otherwise in a credit line to the material. If material is not included in the article's Creative Commons licence and your intended use is not permitted by statutory regulation or exceeds the permitted use, you will need to obtain permission directly from the copyright holder. To view a copy of this licence, visit http://creativecommons.org/licenses/by/4.0/ The Creative Commons Public Domain Dedication waiver (http://creativecommons.org/publicdomain/zero/1.0/) applies to the data made available in this article, unless otherwise stated in a credit line to the data. 


\section{Background}

The care of older patients in the emergency department (ED) is often complex due to comorbidity, polypharmacy [1], cognitive and functional decline. In addition, older patients are frequent visitors who often present atypical symptoms, require more extensive diagnostic workup, stay longer in the ED, and are more often admitted to inpatient care [2-5]. Research on innovative care models for older ED patients is therefore a high priority [6]. Geriatric EDs incorporating various components of staff training, screening tools, and post-ED resources have evolved [7-9]. Collaborating medical and nursing associations have endorsed guidelines recommending olderfriendly ED environments, screening of all geriatric patients for high risk of adverse outcomes, and components of a comprehensive geriatric assessment (CGA) $[10,11]$. The American College of Emergency Physicians (ACEP) has launched an accreditation program, where EDs can chose to implement these ED geriatric guidelines at three different levels [12].

CGA is performed by interdisciplinary teams using multidimensional screening tools to assess medical, social and functional needs [13]. For older patients admitted to acute care wards designated for CGA the evidence of being alive and living at home is robust, but it is inconclusive in the ED setting [14-16]. Some studies of consultant geriatrician-led CGA in EDs have reported reduced hospital admission rates [17]. However, CGA is time consuming and should be reserved for frail ED patients, who need to be identified by a validated screening tool [18]. Although a consensus group has defined physical frailty [19], a lack of consensus on its operational definition [20-22], poor agreement between different frailty scores [23], and no gold standard for screening frail ED patients [24-28] persists. This may be a barrier to acquire the additional resources for ED staff training and geriatric interventions.

Healthcare teams improve the quality of care and patient safety [29-32] and the principles of efficient teamwork in EDs have been summarized by researchers [33, 34]. We have previously reported that interprofessional teamwork in an ED reduced the ED length of stay (LOS) compared to two common triage strategies [35]. We lacked resources to implement the geriatric ED guidelines or CGA but were able to dedicate one interprofessional team and an older-friendly area to improve the care for older patients. The aim of the study was to evaluate this pilot project and our research question was: Can a dedicated emergency team and area for older people reduce the hospital admission rate?

\section{Methods}

This was an observational before-and-after study conducted at Södersjukhuset, a 600-bed urban teaching hospital with 110,000 adult ED visits per year in Stockholm, Sweden. Patients 80 years or older accounted for $15 \%$ of the visits, although they only constitute $5 \%$ of the Swedish population. Most patients presented to the Swedish EDs without first seeing a general practitioner. Like many acute hospitals, this hospital had only acute care wards and no geriatric wards. This meant that older patients were transferred for geriatric inpatient care after an acceptance for admission by the receiving hospitals.

\section{Study population \& periods}

We included all ED visits by patients 80 years or older arriving during 45 consecutive weekdays of the project from 2016.09.26 to 2016.11.28 and the corresponding weekdays in the previous year from 2015.09.28 to 2015.11.30 with only regular emergency teams for adult patients of mixed ages. The project was not staffed on Friday 4 Nov 2016, we therefore excluded this day and the corresponding Friday 6 Nov 2015. The lack of consensus on a standard geriatric age limit has caused previous studies to use a wide range of cut-off ages from 60 to 85 years $[17,18,36]$. Considering the high level of independence among Swedish people 60 years or older, we included the oldest age category, 80 years or older, of the yearly report of the Swedish National Board of Health and Welfare (Socialstyrelsen). The ED LOS of this age group is also a national quality measure [5].

\section{Intervention}

During the intervention period in 2016, an interprofessional team of regular ED medical and nursing staff was dedicated to the geriatric module, a calmer area where ten hospital beds replaced ED gurneys and hot food was available. The staff received no special geriatric training and CGA tools were not introduced. This geriatric module operated from Monday 8 am to Friday 3:30 pm. It was staffed by an emergency physician or a senior resident, an intern, a registered nurse, two nursing assistants, and a specialist nurse from 8 am to $9 \mathrm{pm}$, but only a registered nurse and a nursing assistant during night shifts. The specialist nurse had expertise in discharge planning for older patients and networked with local geriatric hospitals. Such specialist nurses were also available for the regular ED during both study periods, but as consultants rather than team members. They had a case management approach by focusing on the older patients' need for more care or service at home and facilitated the transition to geriatric or primary care. However, they did not have a standardized approach to evaluate the older patients, for example, with regard to fall risk or cognitive function. The interprofessional work process was otherwise similar in the geriatric module and the regular ED during both periods and has been described in our previous studies $[35,37]$. 
All patients 80 years or older were eligible for the geriatric module, but younger patients 65 to 79 years old with comorbidities could also be accepted by the geriatric team. High-acuity patients arriving with prehospital alert or needing continuous monitoring of unstable vital signs were excluded, because the older-friendly area lacked the necessary equipment. The excluded patients would have been assigned the red or orange acuity level if the 5-level Rapid Emergency Treatment and Triage System (RETTS) [38] had been in use. However, the triage teams and RETTS had been replaced, when interprofessional teamwork was introduced in November 2014. Instead of assigning each patient an acuity level, a senior nurse in each teamwork module was responsible for the queueing patients and communicated highpriority patients to the other team members [35]. This senior nurse recruited older patients from the registration or the other teamwork modules, when space became available in the geriatric module. This module was estimated to enrol two new geriatric patients per hour between 8 am and $9 \mathrm{pm}$. The capacity was not enough to enrol all eligible patients, especially during peak hours.

\section{Outcome measures and data collection}

The primary outcome measure was the combined proportion of patients admitted to acute care wards at the study hospital and those transferred to receiving hospitals. The secondary outcome measure was the ED LOS, measured as the time interval from registration at ED arrival to departure. We retrospectively collected deidentified patient data from the electronic ED registry and retrieved the variables age, sex, arrival mode, chief complaint and disposition of the patients. The time of arrival and departure were also extracted to calculate the ED LOS. From the hospital bed occupancy registry, we collected data of available in-hospital beds and the number of inpatients at 6 am each weekday during the study periods.

\section{Statistical analysis}

The data was imported to $\mathrm{R}$ version 3.2.4 (The R Foundation for Statistical Computing, Vienna) and IBM SPSS Statistics version 26 for statistical analysis. We used Pearson's $\chi^{2}$ test to compare proportions and the MannWhitney-Wilcoxon test to compare mean values. Since the distribution of ED LOS is heavily skewed with a short LOS for most patients and few with very long LOS, we used median values to compare the study groups and obtained 95\% confidence intervals (CI) by bootstrap sampling. We also used bootstrap sampling to simulate a 2015 group with the same chief complaints and arrival modes as that of the geriatric module in 2016.
We used linear regression analyses to explore the differences in patient and background characteristics between the study periods, with the ED LOS as the dependent variable. We checked that that each model met the normality and homogeneity assumptions and ruled out collinearity. The statistical significance level was set at the two-tailed $p$-value of 0.05 for all outcome measures.

\section{Results}

In the period with only regular team modules from 2015.09.28 to 2015.11.30, we included 2207 arrivals by patients 80 years or older from a total of 13,952 adult arrivals. From 14,627 adult arrivals in the intervention period from 2016.09.26 to 2016.11.28, we included 2377 arrivals by patients 80 years or older. Of these, 634 (26.7\%) patients received care in the geriatric module and the remaining $1743(73.3 \%)$ in the regular ED (Fig. 1).

During the intervention period in 2016, 948 patients were treated in the geriatric module with a mean arrival rate ranging from 1.7 to 2.3 patients per hour from 8 am to $9 \mathrm{pm}$. Of these, 634 patients were 80 years or older with a mean hourly arrival rate ranging from 1.3 to 1.9 . The hourly arrival rate of all 2377 patients 80 years or older reached a maximum of 5.3 at $1 \mathrm{pm}$, which exceeded the estimated capacity of two patients per hour in the geriatric module.

\section{Patient characteristics}

The proportion of patients 80 years or older and the distribution of age, sex, arrival mode, and chief complaint were similar in both periods. In the intervention period, the distribution of arrival mode and chief complaint differed between the geriatric module and regular ED. High-acuity patients received care in the regular ED, where the most common chief complaints were breathing problem, neurological deficit and chest pain. By contrast, patients presenting head injury, abdominal pain and malaise were more likely to receive care in the geriatric module, where a larger proportion arrived by ambulance without prehospital alert (Table 1).

\section{Background characteristics}

The mean daily ED volume was larger in the intervention period, 335.0 (SD 27.1) arrivals compared to 321.5 (SD 27.3) in $2015(p<0.01,95 \%$ CI: 11.9 to 15.0$)$. The hospital's mean in-bed occupancy rate for the wards receiving patients from the adult ED was higher in the intervention period, $99.1 \%$ (SD 2.8) compared to $92.8 \%$ (SD 3.0) in $2015(p<0.01,95 \%$ CI: 5.1 to $7.6 \%)$. This was a combined effect of a larger number of in-patients in 2016, mean 452 (SD 14.1) compared to 434 (SD 13.7) in 2015, and fewer in-beds in 2016, mean 461 (SD 7.1) 


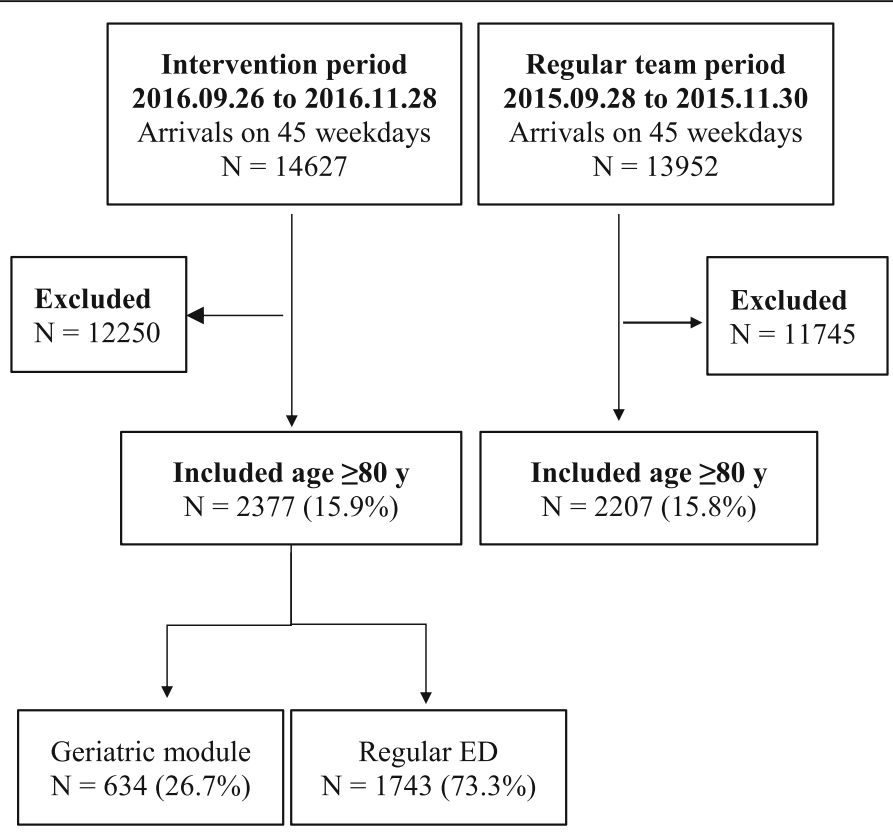

Abbreviations: $\mathrm{ED}=$ emergency department; $\mathrm{N}=$ number of arrivals.

Fig. 1 Flow diagram of the study population. Patients 80 years or older arriving to the emergency department (ED) on weekdays in the intervention period 2016 and the corresponding days in the 2015 period were included. In the intervention period, older patients either received care in the geriatric module, or in the regular ED

compared to 471 (SD 6.9) in 2015. The number of inbeds was reduced from June 2016, when the emergency department closed its 10-bed Observation ward. In the 2015 period, 55 patients 80 years or older were admitted to this Observation ward. Of these, 13 patients were moved to an acute care ward, 11 were transferred to receiving hospitals, and 31 were discharged home. All patients left the ward on the same day or the day after admission, except one who was moved to an acute care ward after 2 days.

\section{Outcome measures}

A smaller proportion of the included patients was admitted to acute care wards at the study hospital in the intervention period, $45.2 \%(N=1074)$ compared to $50.8 \%$ $(N=1121)$ in $2015(p<0.01)$. At the same time, a larger proportion of the patients was transferred to receiving hospitals in the intervention period, $16.5 \%(N=392)$ compared to $14.0 \%(N=310)$ in $2015(p=0.02)$. This means that the combined proportion of patients admitted to acute care wards and those transferred to receiving hospitals was lower in the intervention period, $61.7 \%$ compared to $64.8 \%$ in 2015 ( $p=0.03)$. In addition, a larger proportion of the patients was discharged to home in the intervention period, $36.7 \%(N=872)$ compared to $33.8 \%(N=745)$ in the 2015 period $(p=0.04)$ (Table 2$)$.

The median ED LOS was longer in the intervention period, $330 \mathrm{~min}$ (95\% CI: 322 to 337) compared to 275 min (95\% CI: 267 to 283) in the 2015 period. However, differences in background characteristics could have influenced the ED LOS. We used multi-variate linear regression analysis to explore these differences, in which we also included patient age, sex and arrival mode as predictor variables. The analysis indicated $84 \mathrm{~min}$ longer ED LOS for patients treated in the geriatric module (Table 3).

To compare patients in the geriatric module in 2016 to those who would have been eligible if the geriatric module had been introduced in 2015, we simulated 10, 000 bootstrap samples. Each sample consisted of 634 patients from the 2015 period with the same distribution of chief complaint and arrival mode as those of the geriatric module in 2016. In the bootstrap samples, $44.1 \%$ (95\% CI: 39.5 to $48.8 \%$ ) of the patients were admitted to acute care wards and $18.0 \%$ (95\% CI: 14.5 to $21.7 \%$ ) were transferred to receiving hospitals, which means a combined admission rate of $62.1 \%$ (95\% CI: 56.3 to $68.0 \%$ ). The proportion of patients discharged to home was 37.2\% (95\% CI: 32.8 to $41.6 \%$ ) and the median ED LOS for all patients in the bootstrap samples was $291 \mathrm{~min}$ (95\% CI: 227 to 307 ).

\section{Discussion}

This study evaluated a geriatric intervention, where an interprofessional team of ED medical and nursing staff and an older-friendly area were dedicated to older 
Table 1 Patient characteristics

\begin{tabular}{|c|c|c|c|c|}
\hline & \multicolumn{3}{|c|}{2016 intervention period } & \multirow{2}{*}{$\begin{array}{l}2015 \text { period } \\
\text { Total }\end{array}$} \\
\hline & Geriatric module & Regular ED & Total & \\
\hline Arrivals age $\geq 80$ years, $N$ & 634 & 1743 & 2377 & 2207 \\
\hline Mean age, years (SD) & $86.7(4.7)$ & $86.4(4.7)$ & $86.4(4.7)$ & $86.6(4.6)$ \\
\hline Sex & N (\%) & N (\%) & $\mathrm{N}(\%)$ & N (\%) \\
\hline Male & $258(40.7)$ & $683(39.2)$ & 941 (39.6) & $871(39.5)$ \\
\hline Female & $376(59.3)$ & $1060(60.8)$ & $1436(60.4)$ & $1336(60.5)$ \\
\hline \multicolumn{5}{|l|}{ Arrival mode } \\
\hline Prehospital alert & $1(0.2)$ & $235(13.5)$ & $236(9.9)$ & $239(10.8)$ \\
\hline Ambulance/helicopter & $370(58.4)$ & $902(51.7)$ & $1272(53.5)$ & $1186(53.7)$ \\
\hline Other & $263(41.5)$ & $606(34.8)$ & 869 (36.6) & $782(35.4)$ \\
\hline \multicolumn{5}{|l|}{ Top 10 chief complaints } \\
\hline Breathing problem/dyspnoea & $41(6.5)$ & $232(13.3)$ & $273(11.5)$ & $287(13.0)$ \\
\hline Chest pain & $22(3.5)$ & $163(9.4)$ & $185(7.8)$ & $190(8.6)$ \\
\hline Hip injury & $37(5.8)$ & $121(6.9)$ & $158(6.6)$ & $163(7.4)$ \\
\hline Head injury & $59(9.3)$ & $95(5.5)$ & $154(6.5)$ & $140(6.3)$ \\
\hline Limb swelling/pain & $46(7.3)$ & $94(5.4)$ & $140(5.9)$ & $159(7.2)$ \\
\hline Abdominal pain & $50(7.9)$ & $81(4.6)$ & $131(5.5)$ & $159(7.2)$ \\
\hline Stroke/neurological deficit & $13(2.1)$ & $97(5.6)$ & $110(4.6)$ & $119(5.4)$ \\
\hline Malaise & $41(6.5)$ & $50(2.9)$ & $91(3.8)$ & $133(6.0)$ \\
\hline Arrhythmia & $2(0.3)$ & $91(5.2)$ & $93(3.9)$ & $65(2.9)$ \\
\hline Vertigo & $28(4.4)$ & $36(2.1)$ & $64(2.7)$ & $74(3.4)$ \\
\hline
\end{tabular}

Patients 80 years or older arriving to the emergency department (ED) on 45 weekdays in the intervention period from 2016.09 .26 to 2016.11 .28 and the corresponding weekdays from 2015.09.28 to 2015.11.30 were included. In the intervention period, these patients either received care in the geriatric module, or in the regular ED. Abbreviations: ED Emergency department, $N$ Number, SD standard deviation

patients. Our main finding was a lower total hospital admission rate for all patients 80 years or older during the intervention period, $61.7 \%$ compared to $64.8 \%$ during the corresponding period in the previous year. The difference was larger for patients treated in the geriatric module, $51.1 \%$ compared to $62.1 \%$ for patients with the same distribution of chief complaint and arrival mode in 2015.
The arguments for reducing the hospital admissions of older patients are not merely economical. For them, acute hospitalization is a major risk by causing an irreversible decline of the functional status, in addition to the risks of complications and adverse events [39, 40]. Studies of inappropriate hospital admissions have reported that a significant proportion of the older

Table 2 Outcome measures

\begin{tabular}{|c|c|c|c|c|c|}
\hline & \multicolumn{3}{|c|}{2016 intervention period } & \multirow{2}{*}{$\begin{array}{l}2015 \text { period } \\
\text { Total }\end{array}$} & \multirow[t]{2}{*}{$p$} \\
\hline & Geriatric module & Regular ED & Total & & \\
\hline Arrivals, $\mathrm{N}$ & 634 & 1743 & 2377 & 2207 & \\
\hline \multicolumn{6}{|l|}{ ED LOS, min } \\
\hline Median (95\% Cl) & $390(378-407)$ & $313(304-320)$ & $330(322-337)$ & $275(267-283)$ & $<0.01$ \\
\hline ED disposition & N (\%) & N (\%) & $\mathrm{N}(\%)$ & $\mathrm{N}(\%)$ & \\
\hline Admitted to acute care wards & $198(31.2)$ & $876(50.3)$ & $1074(45.2)$ & $1121(50.8)$ & $<0.01$ \\
\hline Transferred to receiving hospitals & $126(19.9)$ & $266(15.3)$ & $392(16.5)$ & $310(14.0)$ & 0.02 \\
\hline Discharged to home & $306(48.3)$ & $566(32.5)$ & $872(36.7)$ & $745(33.8)$ & 0.04 \\
\hline Other & $4(0.6)$ & $35(2.0)$ & $39(1.6)$ & $31(1.4)$ & 0.51 \\
\hline
\end{tabular}

Emergency department (ED) length of stay and dispositions for patients 80 years or older in the intervention period from 2016.09.26 to 2016.11.28 and the corresponding days from 2015.09.28 to 2015.11.30. In the intervention period, these patients either received care in the geriatric module, or in the regular ED. Abbreviations: Cl Confidence interval, ED Emergency department, $N$ Number; LOS Length of stay, SÖS Södersjukhuset 
Table 3 ED length of stay (minutes) as the dependent variable in linear regression analysis

\begin{tabular}{|c|c|c|c|c|}
\hline Predictor variable & Range & Beta & Std Error & Sig. \\
\hline (Constant) & & -62.833 & 126.981 & 0.621 \\
\hline Age (years) & 80 to 107 & -0.090 & 0.654 & 0.891 \\
\hline Sex & Female $=1$, Male $=0$ & 12.469 & 6.145 & 0.043 \\
\hline \multicolumn{5}{|l|}{ Arrival by ambulance/helicopter } \\
\hline With prehospital alert & Yes $=1$, No $=0$ & -31.875 & 10.655 & 0.003 \\
\hline Without prehospital alert & $\mathrm{Yes}=1, \mathrm{No}=0$ & 83.383 & 6.538 & $<0.001$ \\
\hline Daily ED volume (Number of arrivals) & 261 to 400 & 0.717 & 0.113 & $<0.001$ \\
\hline Daily hospital in-bed occupancy & 0.662 to 1.050 & 102.182 & 109.141 & 0.349 \\
\hline Geriatric module & Yes $=1, \mathrm{No}=0$ & 84.024 & 9.483 & $<0.001$ \\
\hline Period & $2016=1,2015=0$ & 34.978 & 9.781 & $<0.001$ \\
\hline
\end{tabular}

Abbreviation: $E D$ Emergency department

patients could have received care at lower levels than the acute hospitals [41, 42], and that the social circumstances surrounding the patient influence the physician's decision to admit [43]. This means that some hospital admissions are avoidable by addressing social barriers to be discharged home or by arranging follow-up care. This was even suggested as the primary value of CGA in the ED by the authors of a systematic review of consultant geriatrician-led CGA in the ED [17]. They argued that CGA facilitates the ED teams to safely discharge complex patients who would otherwise have required hospital admission. In these studies, the reduction of hospital admissions ranged from 2.4 to 8.4 percentage points [44-46] and the same day discharge rate increased from 1.4 to $17.1 \%$ [47].

More recent studies of EDs operationalizing the geriatric ED guidelines have been published, where CGA conducted by transitional care nurses in three EDs reduced hospital admission rates by 5,10 , and 17 percentage points, respectively [48]. Another similar Geriatric ED intervention increased the likelihood of discharge with a hazard ratio of 1.2 [49]. These nurses operated as CGA specialists assisting the primary ED staff, and one may assume that the varying effect in these studies depended on the extent CGA results influenced the decisionmaking of the primary ED staff. In contrast, the specialist nurse was a team member of the geriatric module, enabling a close collaboration and sharing of goals for individual patients. Older patients competed with younger and high-acuity patients in the regular ED, whereas in the geriatric module the staff could focus on the complex needs of older patients.

The median ED LOS is seldom reported in geriatric studies. Since CGA is time consuming, one may expect a longer ED LOS. To our knowledge, only one paper has reported a shorter ED LOS with hazard ratios 1.28 to $1.48[49]$.

\section{Limitations}

This study has several limitations. Patients were not randomised, which may have introduced bias when selecting patients to the geriatric module. To account for this, we compared all patients 80 years or older in the intervention period to those in the previous year. A beforeand-after design may not claim a causality between the intervention and the outcomes. The results from this single centre may not be transferable or generalisable to different ED settings.

\section{Conclusions}

This study investigated an interprofessional emergency team and area dedicated to older people, a novel approach which may be considered as a first step to implement the geriatric ED guidelines. We found an association between the geriatric module intervention and a lower hospital admission rate, thereby avoiding the risk for functional decline, complications and adverse events associated to hospitalization. However, future randomised controlled studies are needed, preferably involving multiple centres and including patient experience and functional status as outcome measures.

\section{Abbreviations \\ CGA: Comprehensive geriatric assessment; Cl: Confidence interval; \\ ED: Emergency department; LOS: Length of stay; min: Minutes; N: Number; \\ SD: Standard deviation; SE: Standard error \\ Acknowledgements \\ Niklas Grön, Tobias von Gegerfeldt, and Lars Sturesson provided the ED registry data. Mats Nordahl provided statistical advice.}

\section{Authors' contributions}

$J \mathrm{~L}, \mathrm{TP}$, and NF participated in the initiation and development of the study design. $J L$ and TP performed the literature search with inputs from IM, SP, and NF. JL and TP collected and analyzed the data and wrote the initial draft. IM, SP, and NF participated in critical revisions. All five authors have read and approved the final manuscript. The corresponding author and guarantor is $\mathrm{JL}$. 


\section{Funding}

Stockholm County Council sponsored the study through research and development funds dedicated for the Department of Emergency Care at Södersjukhuset and through grants dedicated for work environment improvement. The funder had no input to the study design, data collection, interpretation, writing of report, or submission for publication. Open Access funding provided by Karolinska Institute.

\section{Availability of data and materials}

The datasets used during the current study are available from the following public repository: https://figshare.com/articles/dataset/Geriatric_module_in_ an_ED/13107281. https://doi.org/10.6084/m9.figshare.13107281.

\section{Ethics approval and consent to participate}

We obtained approval of the Regional Ethical Review Board of Stockholm, reference number 2016/109-31/5. Since all ED visits during the study period were included and each patient was managed according to the ED processes at the time of visit, we did not obtain the patients' consent to participate.

\section{Consent for publication}

We did not obtain the patients' consent to publish, because the results are only reported at an aggregated level where the risk of identifying individual patients is negligible.

\section{Competing interests}

All authors declare: no support from any organisation except Stockholm County Council for the submitted work; no financial relationships with any organization except Stockholm County Council that might have an interest in the submitted work in the previous 3 years; no other relationships or activities that could appear to have influenced the submitted work.

\section{Author details}

${ }^{1}$ Department of Clinical Science and Education, Södersjukhuset, Karolinska Institutet, Södersjukhuset AB, KI SÖS, Sjukhusbacken 10, 11883 Stockholm, Sweden. ${ }^{2}$ Department of Computer Science and Media Technology, Linnaeus University, Växjö, Sweden.

Received: 20 May 2020 Accepted: 20 January 2021 Published online: 10 February 2021

\section{References}

1. Hohl CM, Dankoff J, Colacone A, Afilalo M. Polypharmacy, adverse drugrelated events, and potential adverse drug interactions in elderly patients presenting to an emergency department. Ann Emerg Med. 2001;38(6):66671.

2. Pines JM, Mullins PM, Cooper JK, Feng LB, Roth KE. National trends in emergency department use, care patterns, and quality of care of older adults in the United States. J Am Geriatr Soc. 2013;61(1):12-7.

3. Aminzadeh F, Dalziel WB. Older adults in the emergency department: a systematic review of patterns of use, adverse outcomes, and effectiveness of interventions. Ann Emerg Med. 2002;39(3):238-47.

4. Ukkonen M, Jämsen E, Zeitlin R, Pauniaho S-L. Emergency department visits in older patients: a population-based survey. BMC Emerg Med. 2019;19(1): 20.

5. Uppföljning av hälso- och sjukvårdens tillgänglighet - väntetider i akutsjukvården och fyra tematiska analyser, 2019 [https://www. socialstyrelsen.se/globalassets/sharepoint-dokument/artikelkatalog/ovrigt/2 019-4-10.pdf].

6. Wilber ST. Chapter 3 Geriatric Emergency medicine. In: New Frontiers in geriatrics research - an agenda for surgical and related medical specialties. New York, US: The American Geriatrics Society; 2003.

7. Hogan TM, Olade TO, Carpenter CR. A profile of acute care in an aging America: snowball sample identification and characterization of United States geriatric emergency departments in 2013. Acad Emerg Med. 2014; 21(3):337-46.

8. Salvi F, Morichi V, Grilli A, Giorgi R, Spazzafumo L, Polonara S, et al. Service for acutely ill elderly patients: pattern of use and comparison with a conventional Emergency Department in Italy. J Am Geriatr Soc. 2008;56(11): 2131-8.
9. Southerland LT, Lo AX, Biese K, Arendts G, Banerjee J, Hwang U, et al. Concepts in practice: Geriatric Emergency departments. Ann Emerg Med. 2020;75(2):162-70

10. Quality care for older people with urgent \& emergency care needs [https:// www.rcem.ac.uk/docs/College\%20Guidelines/5z9.\%20Quality\%20Care\%2 ofor\%20older\%20people\%20with\%20urgent\%20and\%20emergency\%2 0care\%20needs.pdf].

11. American College of Emergency Physicians; American Geriatrics Society; Emergency Nurses Association; Society for Academic Emergency Medicine; Geriatric Emergency Department Guidelines Task Force. Geriatric emergency department guidelines. Ann Emerg Med. 2014;63(5):e7-25.

12. Geriatric Emergency Department Accreditation Program [https://www.acep. org/geda/].

13. Parker SG, McCue P, Phelps K, McCleod A, Arora S, Nockels K, et al. What is comprehensive Geriatric assessment (CGA)? An umbrella review. Age Ageing. 2018;47(1):149-55.

14. Conroy SP, Stevens T, Parker SG, Gladman JRF. A systematic review of comprehensive geriatric assessment to improve outcomes for frail older people being rapidly discharged from acute hospital: 'interface geriatrics. Age Ageing. 2011;40(4):436-43.

15. Pilotto A, Cella A, Pilotto A, Daragjati J, Veronese N, Musacchio C, et al. Three decades of comprehensive Geriatric assessment: evidence coming from different healthcare settings and specific clinical conditions. J Am Med Dir Assoc. 2017;18(2):192.e191-11.

16. Berning MJ, Oliveira JESL, Suarez NE, Walker LE, Erwin P, Carpenter CR, et al. Interventions to improve older adults' Emergency department patient experience: a systematic review. Am J Emerg Med. 2020;38(6):1257-69.

17. Jay S, Whittaker P, Mclntosh J, Hadden N. Can consultant geriatrician led comprehensive geriatric assessment in the emergency department reduce hospital admission rates? A systematic review. Age Ageing. 2017:46(3):366-72.

18. Graf CE, Zekry D, Giannelli S, Michel JP, Chevalley T. Efficiency and applicability of comprehensive geriatric assessment in the Emergency department: a systematic review. Aging Clin Exp Res. 2011;23(4):244-54.

19. Morley JE, Vellas B, van Kan GA, Anker SD, Bauer JM, Bernabei R, et al. Frailty consensus: a call to action. J Am Med Dir Assoc. 2013;14(6):392-7.

20. Walston J, Buta B, Xue QL. Frailty screening and interventions: considerations for clinical practice. Clin Geriatr Med. 2018;34(1):25-38.

21. Rockwood K, Howlett SE. Fifteen years of progress in understanding frailty and health in aging. BMC Med. 2018;16(1):220.

22. Lee $H$, Lee $E$, Jang IY. Frailty and comprehensive Geriatric assessment. J Korean Med Sci. 2020;35(3):e16.

23. Aguayo GA, Donneau AF, Vaillant MT, Schritz A, Franco OH, Stranges S, et al. Agreement between 35 published frailty scores in the general population. Am J Epidemiol. 2017;186(4):420-34.

24. Carpenter CR, Shelton E, Fowler S, Suffoletto B, Platts-Mills TF, Rothman RE, et al. Risk factors and screening instruments to predict adverse outcomes for undifferentiated older Emergency department patients: a systematic review and meta-analysis. Acad Emerg Med. 2015;22(1):1-21.

25. O'Caoimh R, Costello M, Small C, Spooner L, Flannery A, O'Reilly L, et al. Comparison of frailty screening instruments in the Emergency department. Int J Environ Res Public Health. 2019;16(19):13.

26. Taylor A, Broadbent M, Wallis M, Marsden E. The predictive validity of the interRAI ED screener for predicting re-presentation within 28 days for older adults at a regional hospital emergency department. Australasian Emerg Care. 2019;22(3):149-55.

27. Jørgensen $R$, Brabrand M. Screening of the frail patient in the emergency department: a systematic review. Eur J Intern Med. 2017;45:71-3.

28. Carpenter CR, Mooijaart SP. Geriatric screeners 2.0: time for a paradigm shift in Emergency department vulnerability research. J Am Geriatr Soc. 2020; 68(7):1402.

29. Debehnke D, Decker MC. The effects of a physician-nurse patient care team on patient satisfaction in an academic ED. Am J Emerg Med. 2002;20(4): 267-70.

30. Morey JC, Simon R, Jay GD, Wears RL, Salisbury M, Dukes KA, et al. Error reduction and performance improvement in the emergency department through formal teamwork training: evaluation results of the MedTeams project. Health Serv Res. 2002;37(6):1553-81.

31. Patel PB, Vinson DR. Team assignment system: expediting emergency department care. Ann Emerg Med. 2005;46(6):499-506.

32. Clancy CM. Ten years after to err is human. Am J Med Qual. 2009;24(6): $525-8$. 
33. Salas E, Rosen MA, King H. Managing teams managing crises: principles of teamwork to improve patient safety in the Emergency room and beyond. Theor Issues Ergon Sci. 2007:8(5):381-94.

34. Fernandez R, Kozlowski SW, Shapiro MJ, Salas E. Toward a definition of teamwork in emergency medicine. Acad Emerg Med. 2008;15(11):1104-12.

35. Liu J, Masiello I, Ponzer S, Farrokhnia N. Can interprofessional teamwork reduce patient throughput times? A longitudinal single-Centre study of three different triage processes at a Swedish emergency department. BMJ Open. 2018;8(4):e019744.

36. Schnitker L, Martin-Khan M, Beattie E, Gray L. Literature review: negative health outcomes and adverse events in older people attending emergency departments: a systematic review. Australas Emerg Nurs J. 2011;14:141-62.

37. Liu J, Masiello I, Ponzer S, Farrokhnia N. Interprofessional teamwork versus fas track streaming in an emergency department - an observational cohort study of two strategies for enhancing the throughput of orthopedic patients presenting limb injuries or back pain. PLoS One. 2019;14(7):e0220011.

38. Wireklint SC, Elmqvist C, Parenti N, Göransson KE. A descriptive study of registered nurses' application of the triage scale RETTSO; a Swedish reliability study. Int Emerg Nurs. 2018;38:21-8.

39. Creditor MC. Hazards of hospitalization of the elderly. Ann Intern Med. 1993; 118(3):219-23.

40. Covinsky KE, Palmer RM, Fortinsky RH, Counsell SR, Stewart AL, Kresevic D, et al. Loss of independence in activities of daily living in older adults hospitalized with medical illnesses: increased vulnerability with age. J Am Geriatr Soc. 2003:51(4):451-8.

41. DeCoster C, Roos NP, Carriere KC, Peterson S. Inappropriate hospital use by patients receiving care for medical conditions: targeting utilization review. Can Med Assoc J. 1997;157(7):889-96.

42. Ingold BB, Yersin B, Wietlisbach V, Burckhardt P, Burnand B, Büla CJ. Characteristics associated with inappropriate hospital use in elderly patients admitted to a general internal medicine service. Aging Clin Exp Res. 2000; 12(6):430-8.

43. Dempsey J. The appropriateness of admissions and the influences on a decision to admit. J Qual Clin Pract. 2000;20(2-3):95-9.

44. Arendts G, Fitzhardinge S, Pronk K, Donaldson M, Hutton M, Nagree Y. The impact of early emergency department allied health intervention on admission rates in older people: a non-randomized clinical study. BMC Geriatr. 2012;12:8.

45. Wright PN, Tan G, liffe S, Lee D. The impact of a new emergency admission avoidance system for older people on length of stay and same-day discharges. Age Ageing. 2014;43(1):116-21.

46. Conroy SP, Ansari K, Williams M, Laithwaite E, Teasdale B, Dawson J, et al. A controlled evaluation of comprehensive geriatric assessment in the emergency department: the 'Emergency frailty unit'. Age Ageing. 2014;43(1): 109-14.

47. Ellis $\mathrm{G}$, Jamieson CA, Alcorn M, Devlin V. An acute Care for Elders (ACE) unit in the emergency department. Eur Geriatr Med. 2012;3(4):261-3.

48. Hwang U, Dresden SM, Rosenberg MS, Garrido MM, Loo G, Sze J, et al. Geriatric Emergency department innovations: transitional care nurses and hospital use. J Am Geriatr Soc. 2018:66(3):459-66.

49. Wallis M, Marsden E, Taylor A, Craswell A, Broadbent M, Barnett A, et al. The Geriatric Emergency department intervention model of care: a pragmatic trial. BMC Geriatr. 2018;18:9.

\section{Publisher's Note}

Springer Nature remains neutral with regard to jurisdictional claims in published maps and institutional affiliations.

Ready to submit your research? Choose BMC and benefit from:
- fast, convenient online submission
- thorough peer review by experienced researchers in your field
- rapid publication on acceptance
- support for research data, including large and complex data types
- gold Open Access which fosters wider collaboration and increased citations
- maximum visibility for your research: over 100M website views per year
At BMC, research is always in progress.
Learn more biomedcentral.com/submissions

